\title{
Movimentos e referenciais curriculares que integram o desenvolvimento do ensino da Matemática no Rio Grande do Sul
}

\author{
Luísa Silva Andrade 1 \\ Carmen Teresa Kaiber ${ }^{2}$
}

\begin{abstract}
RESUMO
Este artigo apresenta aspectos do contexto educativo do Estado do Rio Grande do Sul, Brasil, tendo como fio condutor o desenvolvimento curricular da Matemática nos anos finais do Ensino Fundamental a partir de 1970. A riqueza de dados sobre os movimentos e ações que foram constituindo a educação no Estado, bem como o entendimento sobre a importância dos mesmos, no cenário educativo atual, motivaram a busca pela organização desses achados. Destaca-se a importância, principalmente nas décadas de 1970 e 1980, das ações do Grupo de Estudos sobre o Ensino da Matemática de Porto Alegre (GEEMPA), as quais deram protagonismo a professores e pesquisadores. Emergiu das reflexões em torno da pesquisa o entendimento de que, no Estado, as ações educativas procuram alinhar-se ao que está sendo desenvolvido em nível nacional e estão fortemente relacionadas à visão política que os sucessivos governos têm da educação, o que pode levar a rupturas no trabalho realizado.
\end{abstract}

PALAVRAS-CHAVE: Desenvolvimento Curricular. Currículo de Matemática no Rio Grande do Sul. Ensino de Matemática.

Curricular Movements and Curricular References that Integrate the Development of Mathematics Teaching in Rio Grande do Sul

\footnotetext{
${ }^{1}$ Doutora em Ensino de Ciências e Matemática. Professora da Rede Municipal de Gravataí e de Sapucaia do Sul. Porto Alegre, Rio Grande do Sul, Brasil. https://orcid.org/0000-0001-9437-5767. luisaandrade1 @ yahoo.com.br.

${ }^{2}$ Doutora em Ciências da Educação. Professora do Curso de Matemática e do Programa de Pós-Graduação em Ensino de Ciências e Matemática da Universidade Luterana do Brasil/UlBRA. Canoas, Rio Grande do Sul, Brasil. http://orcid.org/0000-0003-1883-230X.carmen_kaiber@hotmail.com.
} 


\begin{abstract}
This article presents aspects of the educational context of the state of Rio Grande do Sul, Brasil, having as a guiding thread the Mathematics curriculum development in the final years of elementary school, from the 1970s. The richness of data on the movements and actions that constituted the education in the state and our understanding on their importance in the current educational scenario motivated the organization of those findings. We highlight the importance, especially in the 1970s and 1980s, of the actions of the Study Group on the Teaching of Mathematics of Porto Alegre (GEEMPA), which focused on the teachers and researchers. This work emerged from the reflections around the concept that the educational actions in the state of Rio Grande do Sul seek to align with what is being developed at the national level and are strongly related to the political vision that successive governments have had of education, which can lead to disruptions in the work done so far.
\end{abstract}

KEYWORDS: Curriculum Development. Mathematics Curriculum in Rio Grande do Sul. Mathematics Teaching.

\title{
Movimientos y Referencias Curriculares que Integran el Desarrollo de la Enseñanza de las Matemáticas en Rio Grande do Sul
}

\section{RESUMEN}

Este artículo presenta aspectos del contexto educativo del estado del Rio Grande do Sul, Brasil, teniendo como hilo conductor el desarrollo del currículo de Matemáticas en los últimos años de la escuela primaria, desde la década de 1970. La riqueza de datos sobre los movimientos y acciones que constituyeron la educación en el estado y nuestra comprensión de su importancia en el escenario educativo actual motivaron la organización de esos hallazgos. Destacamos la importancia, especialmente en los años setenta y ochenta, de las acciones del Grupo de Estudio sobre la Enseñanza de las Matemáticas de Porto Alegre (GEEMPA), que dio protagonismo a docentes e investigadores. Este trabajo surgió de las reflexiones en torno al concepto de que las acciones educativas en el estado de Rio Grande do Sul buscan alinearse con lo que se está desarrollando a nivel nacional y están fuertemente relacionadas con la visión política que los sucesivos gobiernos han tenido de la educación, que puede conducir a rupturas en el trabajo que se ha realizado hasta ahora. 
PALABRAS CLAVE: Desarrollo curricular. Currículo de Matemáticas en Rio Grande do Sul. Enseñanza de las Matemáticas.

$$
* * *
$$

\section{Introdução}

O processo de organização e desenvolvimento curricular, no Brasil, no que se refere à Matemática, considerando a segunda metade do século XX, é sintetizado por Pires (2008) a partir da compreensão de três marcos: o Movimento Matemática Moderna (MMM), que transcorreu no país, nos anos de 1965 a 1980, o estabelecimento de diretrizes que buscavam contrapor-se ao MMM, lideradas por Secretarias Estaduais e Municipais de Ensino, de 1980 a 1994, e o projeto nacional de reforma, a partir de 1995, cujo documento base são os Parâmetros Curriculares Nacionais (PCN). A esses três marcos apontados pela autora se pode acrescentar, atualmente, um outro, a entrada em vigor da Base Nacional Comum Curricular (BRASIL, 2018a), que se encontra em processo de implementação nos sistemas educacionais em nível federal, estadual e municipal.

Pires (2000) pondera que o Movimento Matemática Moderna chegou ao Brasil no momento em que o tecnicismo dominava as práticas escolares brasileiras. Sobre essa questão, Fiorentini (1995) diz que, do confronto entre o MMM e a pedagogia tecnicista, surge a combinação tecnicismo-formalismo, de origem norte-americana, que se instalou no Brasil no fim dos anos 60, aqui permanecendo até o final da década de 70. Essa proposta tinha por objetivo otimizar os resultados da escola, tornando-a eficiente e funcional, e cuja finalidade seria preparar o indivíduo para compor a sociedade, tornando-o capaz e útil.

No decorrer dos anos 80 e 90, reformas curriculares foram propostas e realizadas em vários países, sendo esse período, no Brasil, caracterizado como um período em que se desenvolveu o processo de abertura democrática após o 
período de ditadura que se implantou em 1964 (PIRES, 2000). Segundo Nacarato, Mengali e Passos (2009), os currículos mundiais elaborados, nesse período, possuíam características semelhantes quanto ao ensino da disciplina: não linearidade do currículo, busca da aprendizagem com significado, valorização da resolução de problemas, dentre outros. No entanto, ainda predominava a ênfase nos conteúdos e nos procedimentos de resolução.

Garnica (2007) menciona que o clima de abertura política dos anos 80 possibilitou aspirações acerca da construção de uma escola com base em valores democráticos. Dessa forma, segundo o autor, surgiu a Proposta Curricular para o ensino de primeiro grau, a ser implantada no Estado de São Paulo - e outras propostas gerenciadas por Secretarias Municipais e Estaduais de Educação. Pires (2000) pondera que, no âmbito dessas propostas, a Matemática passou a ser vista com uma dupla função no currículo: como necessária em atividades práticas que envolvem aspectos quantitativos da realidade e como área que desenvolve o raciocínio lógico, as capacidades de abstrair, generalizar e transcender ao que é imediatamente sensível.

Porém, no ano de 1996, no contexto de retomada da democratização do país (PIRES, 2000) e depois de anos tramitando no Congresso, foi aprovada e sancionada a nova Lei de Diretrizes e Bases da Educação Nacional - LDBEN, Lei no 9394/96 (BRASIL, 1996). Baseada no princípio do direito universal à educação para todos, a LDBEN trouxe mudanças significativas em relação às leis anteriores, como a inclusão da educação infantil (creches e pré-escolas) como primeira etapa da educação básica e o estabelecimento da obrigatoriedade e gratuidade do Ensino Médio.

Assim, nesse período em que uma nova LDBEN passou a vigorar, emergiu, no cenário educacional brasileiro, o que Pires (2008) apontou como o desenvolvimento de um projeto nacional de reformas educativas que, segundo a autora, se constitui no terceiro marco no processo de organização e desenvolvimento curricular no Brasil, a partir da segunda metade do século XX, cujo documento base foram os PCN (BRASIL, 1998). 
Para Pires (2000), os PCN (BRASIL, 1998) trouxeram contribuições inovadoras com relação ao ensino da Matemática, dentre as quais destaca: a Matemática vista como compreensão e leitura do mundo, desenvolvimento da capacidade de resolver problemas, o espírito de investigação e a percepção de que a disciplina pode ser desafiante e interessante para o estudante.

Considerado aqui, como o início de um quarto período no processo de organização e desenvolvimento curricular, no Brasil, no ano de 2014 foi aprovado o Plano Nacional de Educação (PNE), com vigência por dez anos, que enfatizava a necessidade de haver uma base comum nos currículos garantindo, porém, as diversidades regional e local. Surgiu, nesse contexto, um movimento para a construção de uma base curricular comum a todo o território nacional, que teve uma primeira versão lançada e posta para consulta pública, em setembro de 2015, sendo que, em dezembro de 2017, a Base Nacional Comum Curricular (BNCC) para a Educação Infantil e Ensino Fundamental foi aprovada pelo Conselho Nacional de Educação e, em 2018, foi aprovada, por esse mesmo conselho, a Base para o Ensino Médio (BRASIL, 2018a).

A BNCC é um documento normativo que serve como suporte para elaboração e adaptação dos currículos em todo país. As redes e escolas têm autonomia para elaborar, por meio do currículo, metodologias de ensino, abordagens pedagógicas e avaliações, incluindo elementos da diversidade local, tendo a base e os currículos papéis complementares (BRASIL, 2018a). $\mathrm{O}$ documento o qual apresenta a base aponta que a mesma indica o rumo da educação, mostrando aonde se quer chegar, enquanto os currículos traçam os caminhos, definindo “[...] o conjunto orgânico e progressivo de aprendizagens essenciais que todos os alunos devem desenvolver ao longo das etapas e modalidades da Educação Básica [...]” (BRASIL, 2018a, p. 07).

Considerando-se os apontamentos apresentados, destaca-se a importância de se ter conhecimento acerca dos movimentos de construção e reformas da educação brasileira como um todo, que não constituem fatos ou acontecimentos desvinculados dos movimentos políticos e sociais internos, 
nem tampouco, dos movimentos de reformas educativas que ocorrem em todo o mundo. Do mesmo modo, considera-se pertinente conhecer o cenário educativo do Estado do Rio Grande do Sul e como os movimentos e reformas anteriormente mencionados no cenário nacional se desenvolveram no Estado.

A riqueza de dados sobre os movimentos e ações que foram constituindo a educação no Estado e o entendimento sobre a importância dos mesmos no cenário educativo atual motivaram a busca pela organização desses achados. Tais dados foram obtidos no contexto do desenvolvimento de uma pesquisa, de base qualitativa, realizada no âmbito de uma tese de doutorado (ANDRADE, 2014) a qual teve como objetivo investigar o desenvolvimento da Matemática no Ensino Médio de escolas públicas estaduais do Rio Grande do Sul, sob a perspectiva do Enfoque Ontossemiótico do Conhecimento e da Instrução Matemática, como possibilidade teórica para análise e organização de currículos de Matemática para esse nível de ensino. Particularmente no que se refere aos dados apresentados neste artigo, foi realizada uma análise documental em um conjunto de documentos publicados pela Secretaria de Educação do Estado do Rio Grande do Sul, os quais serão destacados ao longo do texto.

Assim, o presente artigo busca trazer elementos, os quais se consideram significativos no que se refere ao desenvolvimento curricular, no âmbito da Matemática, no Estado do Rio Grande do Sul, sob a perspectiva dos movimentos e das reformas educacionais que influenciaram o cenário educativo do Estado, bem como dos referenciais curriculares que, efetivamente, chegaram às escolas.

\section{O Currículo de Matemática no Rio Grande do Sul: anos 1970-1980}

Inicia-se essa reflexão sobre as ideias e movimentos que, ao longo das últimas décadas, têm contribuído para estruturar e organizar o currículo, especialmente o de Matemática, no Rio Grande do Sul, a partir do que, na literatura, ficou destacado como as influências do Movimento Matemática 


\section{Moderna (MMM).}

Fischer (2006) destaca que, no Brasil, coincidindo com o Movimento Matemática Moderna que chegava ao país, houve a mobilização e organização de grupos regionais os quais buscavam difundir o movimento e, a partir de estudos, pesquisas, atividades e processos formativos, discutir, refletir e produzir conhecimento sobre os processos de ensino e de aprendizagem da Matemática.

Nesse contexto, em setembro de 1970, foi criado, em Porto Alegre, o Grupo de Estudos sobre o Ensino da Matemática de Porto Alegre (GEEMPA), tendo à frente a professora Ester Pillar Grossi - atual presidente do GEEMPA e figura de maior influência no Grupo em toda a sua trajetória, como fundadora e pesquisadora. Naquele momento, o Grupo reuniu profissionais decididos a investirem em pesquisas e ações voltadas para a melhoria do ensino da Matemática, vinculadas à formação e ao desenvolvimento cognitivo, sob uma perspectiva construtivista piagetiana (GROSSI, 2005). O mesmo foi fundado em um momento em que "[...] a influência da matemática moderna já penetrava nos livros didáticos e já era tema de debate público" (BÜRIGO, 1989, p. 138).

Conforme Fischer (2006), os fundadores do Grupo eram professoras primárias que atuavam no Instituto de Educação General Flores da Cunha de Porto Alegre, local onde se realizou a assembleia de fundação do GEEMPA, e já apresentavam, naquela época, uma trajetória profissional com participação efetiva no MMM, o que se refletiu nos trabalhos produzidos pelo Grupo, especialmente em sua primeira década de existência.

De acordo com Grossi (1994), os trabalhos produzidos pelo grupo, nesse período, representaram um nível de caminhada didática e foram marcados pela

[...] depuração dos livros-texto de mil incorreções matemáticas, ao mesmo tempo em que bons matemáticos passaram a se ocupar do ensino, criando atividades didáticas logicamente condizentes com os 
conteúdos visados, o que foi um avanço extraordinário (GROSSI, 1994, p. 97).

Segundo Fischer (2006), a trajetória do GEEMPA, ao longo dos anos, possui um papel de destaque na constituição do currículo e na formação de professores em Matemática, por meio da realização de encontros, seminários, palestras, reuniões de estudo, entre outras atividades.

A partir de 1983, de acordo com Fischer (2006), o GEEMPA ampliou seus objetivos estatutários e passou a dedicar-se à pesquisa na área da Educação e, mesmo mantendo a sigla, alterou sua denominação para Grupo de Estudos sobre Educação, Metodologia de Pesquisa e Ação, distanciando-se de ações voltadas ao ensino e à aprendizagem da Matemática, sem, todavia, abandoná-los. Atualmente, as finalidades do GEEMPA $^{3}$ voltam-se para o estudo e a pesquisa, visando desenvolvimento das ciências da educação e à realização de ações efetivas para melhoria da qualidade do ensino.

No período em que o GEEMPA iniciava suas ações, circulava, no Estado, a Revista do Ensino do Rio Grande do Sul que, na década de 1970, buscou difundir os ideários do MMM por meio de orientações para os docentes de como proceder com essa "nova Matemática". Segundo Pereira (2010), a referida revista foi editada, pela primeira, vez em setembro de 1939, sendo publicada até o ano de 1942, considerada a primeira fase de edição. Já em uma segunda fase de 1951 a 1978, passou a ser uma publicação oficial da supervisão técnica do Centro de Pesquisas e Orientações Educacionais do Rio Grande do Sul (CPOE/RS), vinculado à Secretaria de Educação e Cultura do Estado do Rio Grande do Sul.

Esse periódico, na visão de Pereira (2010), teve grande influência na educação, nas décadas de 50, 60 e 70, sendo um observatório privilegiado dos discursos e práticas educativas de uma época e um instrumento de veiculação da intenção político-pedagógica da Secretaria de Educação do Rio Grande do

\footnotetext{
${ }^{3}$ Informações tomadas em www.educaedu-brasil.com/centros/geempa--grupo-de-estudos-sobre-educacao-metologiade-pesquisa-e-acao-uni3227
} 
Sul. De acordo o autor, a Revista do Ensino/RS ofereceu um importante material, envolvendo a articulação de discursos sobre a Matemática com o objetivo de orientar o professor dessa disciplina.

Conforme Bastos (2005), evidências das marcas deixadas pela influência da Revista são observadas, ainda hoje, nas práticas escolares, visto que muito do que se faz (atividades com jogos, uso de cartazes em sala de aula, entre outros) remete às orientações e sugestões presentes na revista. Porém, no ano de 1978, a Revista do Ensino/RS deixou de circular por dificuldades relacionadas à editoração e circulação. Posteriormente, algumas revistas seriam publicadas com o mesmo nome, sob influência de diferentes governos estaduais, mas já não mais com as características apontadas (PEREIRA, 2010).

Percebe-se, no período em questão, movimentos, tanto por parte de grupos de pesquisadores e professores, quanto dos órgãos governamentais estaduais responsáveis, no sentido de estabelecer discussões, reflexões, produção de material e divulgação sobre questões educativas, bem como no que se refere ao ensino da Matemática, particularmente. Porém, no período 1978-1988, além da continuidade do trabalho do GEEMPA, já agora com seu foco de atuação ampliado, não foram encontrados registros de ações de grande porte por parte da Secretaria de Educação no Estado, no que se refere a um trabalho que encaminhasse, junto às escolas, discussões e reflexões sobre a organização das mesmas em relação à constituição de currículos e aos processos de ensino e de aprendizagem, como um todo e, particularmente, em relação à Matemática.

\section{Referenciais e propostas curriculares de Matemática no Rio Grande do Sul: anos 1990-2019}

No período que se seguiu à aprovação da Constituição Federal de 1988, no Rio Grande do Sul, os governos que se sucederam desenvolveram, cada um, projetos para a educação estadual. Assim, os apontamentos apresentados a 
seguir buscam evidenciar as políticas educacionais mais marcantes, no que se refere à organização da escola e seu currículo, propostas para serem implementadas nas escolas estaduais entre os anos 1991 até 2018, durante os mandatos de sete governadores filiados a quatro partidos políticos diferentes. Entre essas, apresenta-se a organização de três referenciais curriculares e três propostas de reestruturação específica para a educação secundária.

Destaca-se que o objetivo desses apontamentos não é a análise e discussão sobre a implementação de tais políticas educacionais, mas fazer uma descrição das mesmas, para que se possa conhecer aspectos das mudanças educacionais que ocorreram no Estado e da constituição dos currículos a serem desenvolvidos nas escolas, particularmente no que se refere à Matemática. A menção aos diferentes governos deve-se ao fato que, notadamente, a cada mudança, relacionam-se propostas e projetos para a educação próprias de cada governo que assume, marcados por rupturas com os processos anteriores.

No período 1991-1994, o governo do Estado, a partir da Secretaria de Educação, implementou o Projeto Melhoria da Qualidade do Ensino, coordenado por um Grupo Interinstitucional formado por quatro Instituições de Ensino Superior ${ }^{4}$.

Segundo Dall'Igna e Cóssio (2011), para efetivação desse projeto, os docentes da rede pública foram orientados, em um primeiro momento, a se reunirem, nas escolas, e elencar temas de interesse para serem discutidos. A partir das demandas apresentadas, um grupo de profissionais das Instituições de Ensino Superior envolvidas no projeto elaboraram um material técnico-pedagógico. Textos foram editados e enviados às escolas, para servirem como subsídio para os professores estudarem e fundamentarem o seu trabalho.

Porém, esse período foi marcado por embates entre os professores estaduais, liderados pelo Centro dos Professores do Estado do Rio Grande do

\footnotetext{
${ }^{4}$ Universidade Regional Integrada (URI), Universidade do Vale do Rio dos Sinos (UNISINOS), Universidade Regional do Noroeste do Estado do Rio Grande do Sul (UNIJUÍ) e Universidade de Cruz Alta (UNICRUZ).
} 
Sul - Sindicato dos Trabalhadores em Educação (CPERS-Sindicato) ${ }^{5}$, e o governo do Estado, em função de outra medida tomada pela Secretaria de Educação, a qual envolvia a implantação de um calendário escolar diferente do até então implementado, o chamado "Calendário Rotativo". Esse calendário previa três inícios de ano letivo distintos, com o objetivo de utilização permanente da estrutura física das escolas.

A questão envolvendo o calendário rotativo acabou polarizando as discussões, no período, e as questões referentes à proposta curricular ficaram em segundo plano, não avançando no sentido de concretizar o que tinha sido proposto inicialmente.

Referente aos anos 1995 a 1998, uma das primeiras ações foi a aprovação da Lei da Gestão Democrática do Ensino Público, Lei Estadual $n^{\circ}$ 10.576, de 14 de novembro de 1995, regulamentando o que previa a Constituição do Brasil de 1988. Segundo Mello (2010), essa lei dispunha sobre eleição de diretores, instituição dos conselhos, nas escolas estaduais, autonomia financeira da escola e tratava do regime de colaboração entre o Estado e municípios na oferta de educação escolar no Estado.

Assim, no contexto do que estava sendo proposto, a melhoria da qualidade de ensino foi incentivada através da Lei Estadual n ${ }^{\circ} 11.125 / 98$, em seu artigo 32, dispondo sobre a atribuição de Prêmio de Produtividade Docente aos membros do Magistério Público Estadual. O valor corresponderia a duas remunerações mensais aos professores que atingissem coeficiente de qualidade escolar a ser definido pelo poder executivo para as escolas estaduais.

De acordo com Mello (2010, p. 129), em relação à gestão de ensino, além da apresentação de diversos programas e ações e fazendo parte do Projeto Estande do Rio Grande, foram organizadas publicações que chegaram até as escolas, por meio de “[...] 09 Cadernos Pedagógicos da Gestão Democrática de

\footnotetext{
${ }^{5}$ O Centro dos Professores do Estado do Rio Grande Do Sul - Sindicato dos Trabalhadores em Educação (CEPERSSindicato) é uma entidade criada pela transformação da Associação Civil denominada "Centro dos Professores do Estado do Rio Grande do Sul" em Sindicato, autônomo, sem vinculação político-partidária, nem discriminação de qualquer natureza, com duração indeterminada, sede e foro na cidade de Porto Alegre e base territorial em todo o Estado do Rio Grande do Sul (Fonte: https://cpers.com.br/wp-content/uploads/2019/02/estatuto.pdf.)
} 
Ensino Público e dos documentos Padrão Referencial de Currículo do Ensino Fundamental e Padrão Referencial de Currículo do Ensino Médio". Os Cadernos Pedagógicos da Gestão Democrática do Ensino Pública envolviam diferentes temáticas, as quais abordavam aspectos pertinentes à gestão, busca da autonomia e qualidade na escola, tais como: autonomia financeira, administração de recursos humanos, regimento escolar, qualificação da gestão, qualificação do ensino, currículo e cidadania, entre outros.

Já a produção do documento Padrão Referencial de Currículo (PRC) ${ }^{6}$ foi iniciada, em 1996, com a elaboração do PRC - Documento Básico (RIO GRANDE DO SUL, 1996) e do PRC - Documento Intermediário (RIO GRANDE DO SUL, 1997) tendo, efetivamente, chegado às escolas, em 1998, através do documento PRC $-1^{\text {a }}$ versão (RIO GRANDE DO SUL, 1998a). O material constituiria "[...] um corpo básico de conhecimentos, que [deveria] servir como referência para o desenvolvimento do processo de ensino e aprendizagem nas escolas do Sistema de Ensino do Rio Grande do Sul" (RIO GRANDE DO SUL, 1998a, p. 52).

Assim, o término de um processo proposto como participativo, já que previa a participação dos professores na construção dos documentos, por meio da formação de grupos de estudos, participação em seminários, jornadas pedagógicas e discussões, nas escolas, resultou na sistematização do documento do PRC - $1^{\text {a }}$ versão (RIO GRANDE DO SUL, 1998a) em catorze cadernos temáticos para serem orientadores das práticas pedagógicas. $\mathrm{O}$ documento propunha o estabelecimento de um referencial flexível e aberto às inovações, que possibilitasse a unidade das diversas concepções e práticas educacionais, em consonância com a LDB n ${ }^{\circ} 9394$ (BRASIL, 1996) e com a Lei da Gestão Democrática do Ensino Público - Lei nº 10.576 (RIO GRANDE DO SUL, 1995).

Dentre os cadernos, destaca-se o de $\mathrm{n}^{0} 13$ do $\mathrm{PRC}-1^{\mathrm{a}}$ versão, que trata da Matemática do Ensino Fundamental cujo objetivo era voltado a uma

\footnotetext{
${ }^{6}$ Processo semelhante desenvolveu-se, quase paralelamente, em nível federal, pelo Governo Fernando Henrique Cardoso para a definição dos Parâmetros Curriculares Nacionais (DALL’IGNA; CÓSSIO, 2011, p. 05).
} 
perspectiva de trabalho por uma Educação Matemática que envolvesse a capacidade de matematizar situações reais, estabelecer relações entre os problemas e realizar atividades articuladas com outras áreas do conhecimento.

Além disso, o documento dava destaque à perspectiva da resolução de problemas como elemento articulador do processo de ensino e de aprendizagem. Explicitava como marcos de aprendizagem o desenvolvimento dos pensamentos aritmético, algébrico-geométrico e do pensamento estatístico probabilístico na busca da produção de significados, da comunicação de ideias e atuação na realidade. A Figura 1 ilustra esses marcos de aprendizagem para o ensino da Matemática no Ensino Fundamental, o que, no material, é denominado alfabetização matemática.

FIGURA 1: Marcos e Conteúdos de Aprendizagem Matemática/Ensino Fundamental

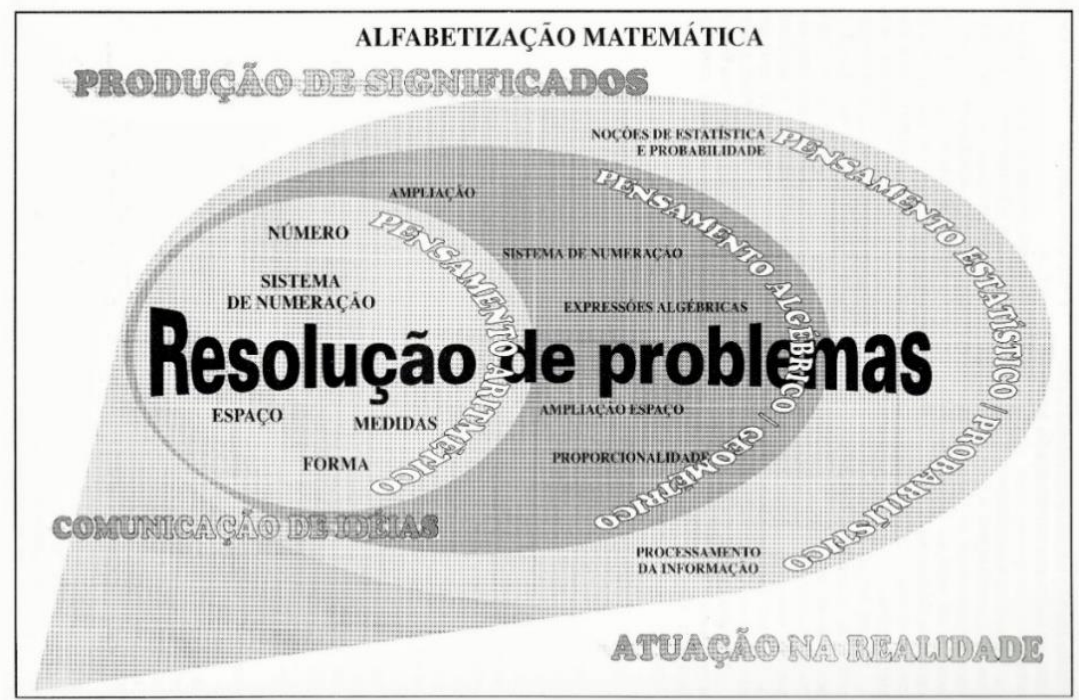

Fonte: PRC $-1^{\mathrm{a}}$ versão - Matemática (RIO GRANDE DO SUL, 1998b, p. 18).

Ressalta-se, no PRC - $1^{\text {a }}$ versão - Matemática, o destacado papel da resolução de problemas como forma de ação ou procedimento mais adequado em cada um dos marcos, tanto para o desenvolvimento da Matemática como para as aprendizagens que o trabalho com o mesmo oportuniza.

O PRC - Ensino Médio (RIO GRANDE DO SUL, 1998c) também foi apresentado aos professores. O mesmo contemplava "reflexões de caráter 
filosófico-educacional em torno de um Referencial para a organização do currículo pleno, isto é, para a programação da totalidade das ações educativas que a escola desenvolveria, a fim de ativar princípios da legislação educacional em vigor no País e no Estado do Rio Grande do Sul" (RIO GRANDE DO SUL, 1998c, p. 09). O caderno também tinha a proposta de ser construído de forma coletiva, tal como ocorreu no Ensino Fundamental, sob o acompanhamento do Departamento Pedagógico Estadual e da Divisão de Ensino Médio.

O caderno de $\mathrm{n}^{\circ} 3$ do PRC - Ensino Médio (RIO GRANDE DO SUL, 1998d) tratava, exclusivamente, da área de Ciência e Tecnologia, abordando os conhecimentos de Matemática e Física. O conjunto desses parâmetros orientadores do planejamento curricular constituía um referencial comum a todas as escolas, a partir do qual a escola construiria o próprio projeto curricular.

Sobre os documentos do PRC (RIO GRANDE DO SUL, 1998a, 1998b, 1998c, 1998d), pode-se dizer que os mesmos apontavam para a consolidação de um corpo básico de conhecimentos para todos os alunos da rede de ensino e, no ideário que o perpassava, havia a crença de que, com o comprometimento da comunidade educacional gaúcha, seria possível alcançar a qualidade da educação no Estado.

No período 1999-2002, o foco das ações foi a busca pela democratização da gestão no sistema estadual de ensino com a promoção e realização de uma Constituinte Escolar, a qual foi desenvolvida em sintonia com o chamado Orçamento Participativo7, com o objetivo de definir princípios e diretrizes, para orientar "[...] a construção de uma Escola Democrática e Popular e criar condições para sua implementação" (RIO GRANDE DO SUL, 1999, p. 05).

A Constituinte Escolar propunha a participação da comunidade escolar (professores, pais, alunos e funcionários) e da comunidade local (sociedade

\footnotetext{
${ }^{7}$ Orçamento Participativo - previa a participação direta e popular na formulação, controle e fiscalização na aplicação de recursos públicos do Estado, de forma transparente e democrática. [...] Envolvia quatro princípios básicos: participação universal do cidadão, discussão dos recursos destinados a investimentos, autorregulamentação do processo, prestação de contas à população (MELLO, 2010, p. 148).
} 
civil, instituições dos poderes público e privado, universidades e movimentos sociais) em diversos fóruns, reuniões, seminários, pré-conferências regionais e conferência estadual, a fim de debater e refletir sobre diretrizes, princípios e metas educacionais, objetivando propostas educacionais. (RIO GRANDE DO SUL, 2000).

Conforme Dall'Igna e Cóssio (2011, p. 06), o projeto, inicialmente, enfrentou o descontentamento dos docentes que, em assembleia do CPERSSindicato, decidiram pela "[...] não participação na Constituinte, alegando o não atendimento à sua pauta de reivindicações. Isso limitou, mas não impediu a participação de escolas e o desenvolvimento do processo".

Segundo Mello (2010), uma Conferência Estadual de Educação foi realizada em agosto de 2000, em Porto Alegre, reunindo 3.500 delegados/as representando todos os segmentos da comunidade escolar e local. Essa conferência resultou na aprovação do documento "Princípios e Diretrizes para a Educação Pública Estadual" (RIO GRANDE DO SUL, 2000). O material serviu de base para a elaboração do Projeto Político-Pedagógico, do Regimento Escolar e dos Planos de Estudo das escolas estaduais.

Além disso, para a realização dos estudos e debates pela comunidade escolar e local, Mello (2010) aponta que a Secretaria do Estado da Educação disponibilizou 25 cadernos temáticos que serviram como subsídio para aprofundamento teórico. Nas escolas, segundo o autor, foram distribuídas cartilhas com orientação para o trabalho com datas comemorativas, tais como: comemoração dos 500 anos do Descobrimento do Brasil, semana da Pátria, entre outros.

Considera-se que as perspectivas das propostas do período 1999-2002 procuravam avançar na democratização dos espaços escolares, mobilizando as comunidades e envolvendo os diferentes segmentos nas discussões e tomada de decisões sobre a política de educação para a rede estadual e os projetos escolares. O trabalho desenvolvido deu ênfase, portanto, a questões amplas da busca de uma visão ou proposta educativa, as quais as comunidades julgassem adequadas ou pertinentes, não focando questões 
específicas da organização curricular ou dos processos de ensino e de aprendizagem no âmbito das disciplinas.

Sobre o período 2003-2006, não foram encontrados registros de ações de grande porte, na área da educação, a serem implementadas nas escolas. $\mathrm{O}$ Relatório das Ações da Secretaria Estadual da Educação destacou projetos pontuais: a Escola Aberta para a Cidadania, a Escola de Tempo Integral e os Jogos Escolares do Rio Grande do Sul.

Segundo Mello (2010), nesse período, no ano de 2005, ocorreu a implantação do projeto piloto do Sistema de Avaliação do Rendimento Escolar do Rio Grande do Sul (SAERS), uma versão das avaliações de larga escala que se realizavam no País. O mesmo foi aplicado em diversas escolas, "abrangendo 75 redes de ensino municipais e 02 Coordenadorias Regionais de Educação, de forma censitária no Ensino Fundamental, com testes de Língua Portuguesa, Matemática e Redação, em escolas urbanas e rurais" (MELLO, 2010, 167). No entanto, apenas em 2007 o SAERS foi obrigatório para as escolas estaduais, abrindo, também, a possibilidade de inclusão das escolas municipais e particulares.

Já no período 2007-2010, uma das ações na área educacional, em âmbito nacional, foi a implantação do Programa Ensino Médio Inovador (BRASIL, 2009), que tinha como objetivo a melhoria da qualidade do ensino médio nas escolas públicas estaduais, reconhecendo a importância do estabelecimento de uma nova organização curricular, baseada em "[...] uma perspectiva de articulação interdisciplinar, voltada para o desenvolvimento de conhecimentos - saberes, competências, valores e práticas" (BRASIL, 2009, p. 13).

No Rio Grande do Sul, em 2009, no âmbito do desenvolvimento do projeto Professor Nota 10 - Valorização do Magistério, o qual direcionou suas ações para a formação continuada e para a elaboração da nova legislação para o sistema educacional do Rio Grande do Sul, a Secretaria de Estado da Educação lançou o Referencial Curricular "Lições do Rio Grande" (RIO GRANDE DO SUL, 2009). 
Esse referencial foi apresentado a partir de material disponibilizado para as escolas contendo os pressupostos que o embasava, bem como destacando habilidades e competências relacionadas trazendo, ainda, indicações de como determinados conteúdos deveriam ser trabalhados junto aos estudantes. Apontava, também, os conteúdos mínimos que deveriam ser desenvolvidos em cada série dos anos finais do Ensino Fundamental e Ensino Médio. Nesse modelo de referencial curricular, as disciplinas afins estavam agrupadas por área de conhecimento, a saber: Linguagens, Códigos e suas Tecnologias: Língua Portuguesa, Literatura, Língua Estrangeira Moderna (Inglês e Espanhol), Educação Física e Arte; Matemática e suas Tecnologias; Ciências da Natureza e suas Tecnologias: Biologia, Física, Química; Ciências Humanas e suas Tecnologias: História, Geografia, Sociologia e Filosofia.

Além disso, o referencial propunha, tanto para o Ensino Fundamental, quanto para o Ensino Médio, duas estratégias: a aprendizagem em contexto e a interdisciplinaridade, além de destacar ideias propostas quanto à metodologia, cuja ênfase está na resolução de problemas e na organização e seleção dos conteúdos.

No documento, a Matemática é percebida como a ciência dos padrões onde

[...] o matemático examina padrões abstratos, sejam eles numéricos, de forma, de movimento, de comportamento, de mudança, de transformação, de posição, e a natureza abstrata dos padrões levaos às notações, às representações e às diferentes formas de descrevêlos.(RIO GRANDE DO SUL, 2009, p. 37).

Com relação à Matemática do Ensino Fundamental, o referencial apontava estar embasado no PCN (BRASIL, 1998) enfatizando a leitura, a discussão e a interpretação de textos, "[...] com o propósito de promover o domínio da linguagem, a compreensão de ideias matemáticas, a interpretação de situações-problema e a familiaridade com a linguagem e com o raciocínio 
lógico-matemático" (RIO GRANDE DO SUL, 2009, p. 53). No Ensino Médio, no documento constava que o estudante deveria elaborar conhecimentos que lhe permitissem ler e interpretar a realidade, desenvolvendo habilidades e competências para atuar na sociedade e na vida profissional, estando, ainda, apto para continuar seus estudos (RIO GRANDE DO SUL, 2009).

A seleção de conteúdos apresentada no documento também seguia as recomendações dos PCN (BRASIL, 1998), mas apresentava competências e habilidades organizadas em três eixos: representação e comunicação; investigação e compreensão; contextualização sociocultural. Esses eixos estavam em consonância com os propostos pelos PCN+ (BRASIL, 2002) e apresentavam um conjunto de habilidades que estavam relacionadas com o ler, o escrever e o resolver problemas.

Um dos objetivos da Matemática, segundo o documento, é estimular o desenvolvimento das formas de pensar, que são constituídas ao longo da história. Essas formas de pensar estão divididas em quatro pensamentos matemáticos, a saber: pensamento aritmético, pensamento algébrico, pensamento geométrico e pensamento estatístico-probabilístico. Assim, no referencial, os blocos de conteúdos estão organizados contemplando os modos de pensar e os conceitos que estruturam a Matemática, conforme a Figura 2.

FIGURA 2: Blocos de Conteúdos, Modos de pensar e os conceitos que estruturam a Matemática

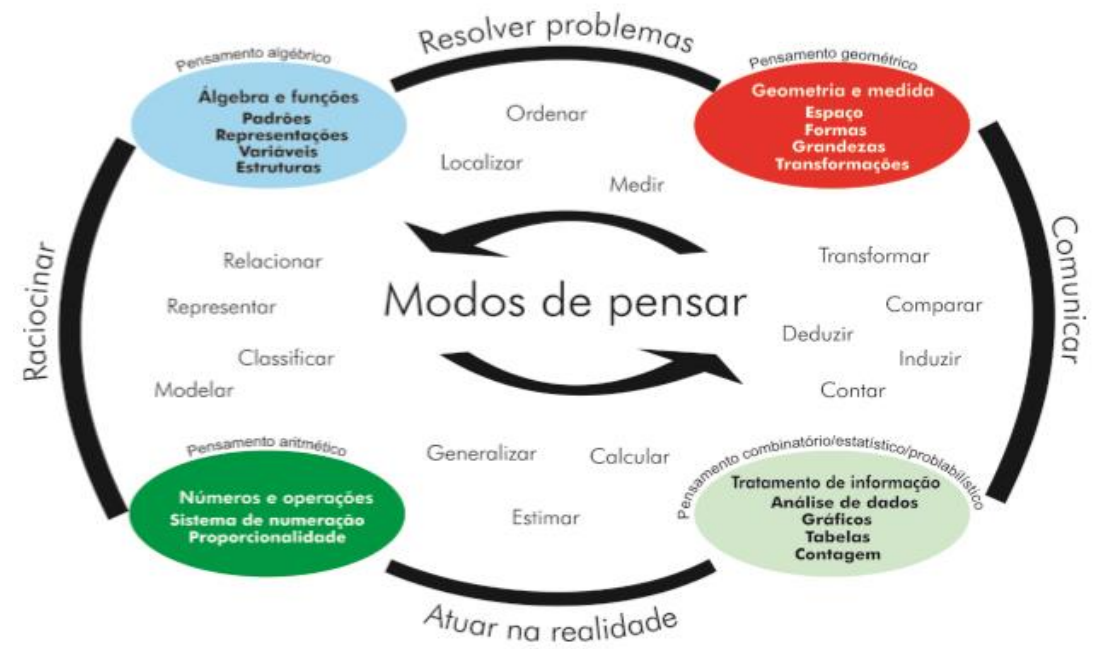

Fonte: Rio Grande do Sul (2009, p. 54). 
Dessa forma, a proposta era que os diferentes modos de pensar estivessem desdobrados em conceitos estruturantes de cada bloco de conteúdo. O documento organizava e apresentava os pensamentos matemáticos a serem desenvolvidos e os conteúdos relacionados em um quadro (RIO GRANDE DO SUL, 2009, p. 55), cuja cor mais intensa definia a prioridade de exploração dos conhecimentos para a série e ano e, ao mesmo tempo, destacava que os mesmos deveriam ser estudados durante toda a educação básica. Buscando exemplificar tal organização, destaca-se, na Figura 3, a organização relativa ao pensamento aritmético.

FIGURA 3: Pensamento Aritmético

\begin{tabular}{|l|l|l|l|l|l|l|}
\hline & & $5^{\mathrm{a} e} \mathrm{6}^{\mathrm{a}}$ & $7^{\mathrm{a}} \mathrm{e} \mathrm{a}$ & $1^{0}$ ano & $2^{0}$ ano & $3^{0}$ ano \\
\hline Pensamento Aritmético & & & & & & \\
\hline \multirow{4}{*}{$\begin{array}{l}\text { Números e operações nos } \\
\text { conjuntos numéricos }\end{array}$} & Naturais & & & & & \\
\hline & Fracionários & & & & & \\
\hline & Inteiros & & & & & \\
\hline & Racionais & & & & & \\
\hline & Irracionais & & & & & \\
\hline & Reais & & & & & \\
\hline & Complexos & & & & & \\
\hline \multirow{5}{*}{ Sistema de numeração } & Base 10 & & & & & \\
\hline & Outras bases & & & & & \\
\hline Proporcionalidade & & & & & & \\
\hline Linguagem e simbologia da Aritmética & & & & \\
\hline
\end{tabular}

Fonte: Rio Grande do Sul (2009, p. 55).

O documento apresentava uma organização similar para os demais modos de pensar (pensamento geométrico, algébrico e tratamento da informação), além de um conjunto de situações de aprendizagem as quais preconizavam a ação do estudante sobre o conhecimento para o desenvolvimento de competências e habilidades destacadas no mesmo.

O Referencial Curricular Lições do Rio Grande chegou às escolas da rede estadual, no ano de 2009, e foi bastante contestado pelos professores, que o consideraram um guia a ser seguido, tirando do docente a prerrogativa de estabelecer como desenvolver os conteúdos. Como no ano de 2011 uma nova gestão de governo se instalou, já nesse ano letivo, o projeto que envolvia o Lições do Rio Grande deixou de ser implementado. 
No período 2011-2014, a gestão da Secretaria do Estado da Educação estabeleceu como prioridades: a democratização da gestão, do acesso à escola, ao conhecimento com qualidade cidadã, à aprendizagem e ao patrimônio cultural, bem como a permanência do aluno na escola, além da qualificação do Ensino Médio e Educação Profissional (RIO GRANDE DO SUL, 2011) com foco no Ensino Médio.

A Proposta Pedagógica para o Ensino Médio Politécnico e Educação Profissional Integrada ao Ensino Médio foi apresentada pela Secretaria de Educação, para as escolas, em outubro e novembro de 2011. A proposta teve aplicação imediata, o que significou a implementação, em 2012, para o $1^{\circ}$ ano do Ensino Médio, em 2013, no $2^{\circ}$ ano e, em 2014, chegou ao $3^{\circ}$ ano. Conforme trechos do documento, a Proposta contemplava

[...] um ensino médio politécnico que tem por base, na sua concepção, a dimensão da politecnia, constituindo-se na articulação das áreas de conhecimento e suas tecnologias com os eixos: cultura, ciência, tecnologia e trabalho, enquanto princípio educativo. Já a educação profissional integrada ao ensino médio se configura como aquisição de princípios que regem a vida social e constroem, na contemporaneidade, os sistemas produtivos (RIO GRANDE DO SUL, 2011, p. 04).

A proposta apresentava as disciplinas articuladas a partir das áreas do conhecimento, a saber, Ciências Humanas e suas Tecnologias, Ciências da Natureza e suas Tecnologias, Linguagens e suas Tecnologias, Matemática e suas Tecnologias e envolvia: a organização curricular por áreas do conhecimento; o apoio no princípio da interdisciplinaridade; a pesquisa que passou a ser assumida como princípio pedagógico; a criação dos chamados Seminários Integrados, que deveriam ser realizados desde o primeiro ano do Ensino Médio, em complexidade crescente, por meio de projetos.

O currículo, segundo o Regimento Referência das escolas de Ensino Médio Politécnico da rede estadual (RIO GRANDE DO SUL, 2012), é visto 
como o conjunto das relações desafiadoras das capacidades de todos, que se propõe a resgatar o sentido da escola como espaço de desenvolvimento e aprendizagem. Os conteúdos são organizados a partir da realidade, da necessidade de sua compreensão e do entendimento do mundo.

Assim, o Currículo do Ensino Médio Politécnico abrangia a chamada Formação Geral (núcleo comum), envolvendo um trabalho interdisciplinar com as áreas de conhecimento, objetivando a organização de um conhecimento associado à tecnologia, visando à apropriação e à integração com o mundo do trabalho e a Parte Diversificada (humana - tecnológica - politécnica), relacionando as áreas do conhecimento ao mundo do trabalho, a partir da experimentação. A articulação desses dois blocos do currículo ocorreria, segundo o documento, por meio de projetos construídos nos seminários integrados, os quais eram de responsabilidade de todos os docentes da escola, com acompanhamento rotativo, constituindo-se em espaços planejados, integrados por professores e alunos.

O período 2015-2018 foi marcado por ações e movimentos que acompanharam as ações, em âmbito nacional, referentes à constituição da Base Nacional Comum Curricular (BNCC), os quais se referem à construção do Referencial Curricular Gaúcho (RCG).

Assim, em dezembro de 2018, pautado sobre as competências gerais estabelecidas pela BNCC (BRASIL, 2018a), o Referencial Curricular Gaúcho (RCG) é homologado, após uma construção dita colaborativa entre Secretaria de Estado da Educação do Rio Grande do Sul (SEDUC/RS), União Nacional dos Conselhos Municipais de Educação do Rio Grande do Sul (UNCME-RS) e União Nacional dos Dirigentes Municipais de Educação do Rio Grande do Sul (UNDIME/RS) e a participação de professores e da sociedade em geral (RIO GRANDE DO SUL, 2018).

O RCG apresenta as especificidades do Estado e orienta os municípios a construírem seus documentos norteadores, que incluirão sua parte diversificada, e as escolas, os seus currículos. O objetivo é estabelecer uma base comum curricular integrada entre as redes municipal, estadual e 
privada. O RCG (RIO GRANDE DO SUL, 2018) está engrenado com as dez macrocompetências essenciais da BNCC (BRASIL, 2018a), e de acordo com o documento "Estas devem ser desenvolvidas ao longo da educação básica, com o objetivo de garantir as aprendizagens de forma espiralada, com foco na equidade e na superação das desigualdades de qualquer natureza” (RIO GRANDE DO SUL, 2018, p. 16).

$\mathrm{Na}$ atualidade, no Estado, está sendo construído e será implementado o novo Ensino Médio (proposta nacional), fruto da conexão entre a BNCC (BRASIL, 2018a) e o RCG (RIO GRANDE DO SUL, 2018) e que tem, como um de seus objetivos, promover o protagonismo do estudante, a valorização da capacidade criativa dos professores e a permanência escolar por meio de aprendizagem com qualidade. Todas as fases de preparação e planejamento visam à implementação, em 2020, em escolas-piloto. Após período de observação e ajustes, no ano de 2022, todas as escolas de Ensino Médio do Rio Grande do Sul (e todas as escolas brasileiras) deverão estar adaptadas.

As ações que envolvem a estruturação do novo Ensino Médio são pautadas segundo os critérios:

- Divisão: a Base Nacional Comum Curricular (BNCC) fará parte de 60\% das matérias estudadas em sala de aula. O restante ficará reservado para uma das áreas específicas, também chamadas de itnerários formativos;

- Flexibilidade: os estudantes terão que escolher um itinerário formativo já no início do ensino médio. As opções são: Linguagens, Matemática, Ciências da Natureza, Ciências Humanas/Sociais e Formação Técnica/Profissional;

- Disciplinas obrigatórias: as disciplinas de Matemática e Português, preservando o direito à língua materna (no caso de indígenas), serão obrigatórias em todo o ensino médio;

- Manutenção de disciplinas: as disciplinas de Educação Física, Artes, Filosofia e Sociologia serão obrigatórias na BNCC (BRASIL, 2018b). 
As recentes ações, as quais resultaram na formulação do RCG (RIO GRANDE DO SUL, 2018) e que estão em processo de implementação, não serão discutidas no presente artigo, justamente por sua transitoriedade. Nesse momento, tanto nas escolas da rede privada como nas estaduais, e nas redes municipais, o momento é de discussão, reflexão e organização de projetos pedagógicos, os quais orientem, em nível local, o proposto na BNCC (BRASIL, 2018a).

\section{Conclusão}

Neste artigo, procurou-se apresentar aspectos dos movimentos e ações referente a organização curricular no Rio Grande do Sul, a partir de propostas colocadas em prática pela Secretaria Estadual de Educação, dando destaque para a área de Matemática.

A leitura sistemática de documentos e de pesquisas que envolvem a questão permite considerar que o sistema educacional gaúcho sempre buscou estar em sintonia com o que estava previsto em lei e sendo realizado em nível nacional, promovendo ações que resultaram, em alguns períodos, em documentos oficiais norteadores das ações nas escolas, no que se refere à organização curricular. Ficou evidente a relação entre os PCN (BRASIL, 1996; 1997; 1998; 1999; 2002; 2006) e os documentos publicados no Rio Grande do Sul, como o Padrão Referencial de Currículo e Lições do Rio Grande. Embora o primeiro enfatize os conteúdos conceituais, procedimentais e atitudinais e o segundo foque na questão das competências e habilidades, em relação à Matemática, é possível identificar a vinculação com os PCN.

Contudo, foi possível perceber que, embora as propostas estivessem norteadas por referenciais consolidados nas áreas de educação e ensino, acompanhando o movimento nacional, talvez não tenham se efetivado nas escolas. Tal entendimento está alicerçado, por um lado, na brevidade de tais propostas (duração de um mandato de um governador) e, por outro, nas polêmicas e embates entre o governo estadual e os professores, que, por vezes, 
se sobrepunham às discussões educacionais e pedagógicas.

Nesse sentido, concorda-se com Dall'Igna e Cóssio (2011) quando afirmam que, no cenário educativo do Rio Grande do Sul, se confirma a descontinuidade de uma política educacional nos projetos de governo, alinhando-se ao que Ganzelli (2003) destaca com relação à política educacional de uma determinada localidade: "A preocupação, presente entre a maioria dos dirigentes, de implementar a sua [proposta] política educacional, considerada, por princípio, como sendo representativa dos interesses da sociedade [...]" (GANZELLI, 2003, p. 52). Outro elemento a considerar nesse processo de mudanças educacionais, no Estado, é o fato de que, no caso dos referenciais curriculares, os documentos orientadores foram concluídos e apresentados às escolas, muitas vezes, nos últimos, senão no último, ano de governo, o que dificultou a consolidação dos mesmos.

No que se refere à Matemática, a leitura sistemática dos documentos que serviram de orientação para a organização da escola e do currículo, ao longo dos últimos 20 anos (Padrão Referencial de Currículo, Projeto Lições do Rio Grande e a Proposta Pedagógica para o Ensino Médio Politécnico e Educação Profissional Integrada ao Ensino Médio), permitiu perceber que o currículo de Matemática, embora enfatizado de diferentes maneiras, implícita ou explicitamente, passou por modificações e adquiriu formas que destacam a importância formativa da Matemática.Tais modificações passam pela ressignificação dos conteúdos a serem ensinados e pelos novos papéis para alunos e professores.

Em relação a esses novos papéis, enfatiza-se a construção do conhecimento pelo aluno, o trabalho em equipe e a comunicação em sala de aula. O professor passou a assumir, nesse contexto, a posição de mediador da aprendizagem, sendo visto como alguém que encoraja os discentes na busca de soluções para os problemas propostos, valorizando os processos de pensamento. A resolução de problemas assumiu um papel central nos processos de ensino e de aprendizagem dos conhecimentos matemáticos.

Já em relação aos conteúdos e/ou áreas do conhecimento, ampliaram- 
se os ramos da Matemática, passando a se considerar Tratamento da Informação (Estatística, Probabilidade, Análise Combinatória) e Grandezas e Medidas como áreas fundamentais para a formação do estudante, além das já tradicionais Números e Operações, Álgebra e Geometria.

Por fim, destaca-se o movimento atual em torno da implementação da Base Nacional Comum Curricular, que tem gerado discussões, reflexões e estudos, iniciando pela própria constituição de uma base nacional comum que, embora prevista no Plano Nacional de Educação, não é unanimidade entre professores, pesquisadores e especialistas. Porém, apesar das discussões e polêmicas em torno da base, no Rio Grande do Sul, as Secretarias Estadual e Municipais de Educação têm trabalhado para trazer a base para dentro das escolas, buscando organizar um currículo alinhado ao proposto na mesma, considerando, também, o proposto no Referencial Curricular Gaúcho.

\section{Referências}

ANDRADE, L.S. Currículos de Matemática no Ensino Médio: um olhar sob a perspectiva do Enfoque Ontosemiótico do Conhecimento e a Instrução Matemática, 2014. Tese (Doutorado em Ensino de Ciências e Matemática) Universidade Luterana do Brasil, Canoas, 2014.

BRASIL. Constituição da República Federativa do Brasil. Presidência da República. 5 de outubro de 1988. Brasília, DF.

BRASIL. Lei n ${ }^{\circ} 9.394$ de 20 de dezembro de 1996. Estabelece as Diretrizes e Bases da Educação Nacional. Presidência da República. Brasília, DF.

BRASIL. Ministério da Educação e do Desporto. Secretaria de Educação Fundamental. Parâmetros Curriculares Nacionais: matemática, terceiro e quarto ciclos. Brasília: MEC/SEF, 1998.

BRASIL. Ministério da Educação. PCN+ Ensino Médio: Orientações Educacionais complementares aos Parâmetros Curriculares Nacionais: ciências da natureza, matemática e suas tecnologias. Brasília: MEC/SEMTEC, 2002.

BRASIL. Ministério da Educação, Secretaria de Educação Básica. Orientações Curriculares para o Ensino Médio: ciências da natureza, matemática e suas tecnologias, Brasília, v. 2, p. 135, 2006. Disponível em: $<$ http://portal.mec.gov.br/seb/arquivos/pdf/book_volume_02_internet.pdf.> Acesso em: 14 mai. 2012. 
BRASIL. Ministério da Educação. Diretrizes Curriculares Nacionais da Educação Básica. Brasília: MEC; SEB; DICEI, 2013. Disponível em: $<$ http://portal.mec.gov.br/index.php?option=com_docman\&view=download\&alias $=1$ 3448diretrizes-curiculares-nacionais-2013-pdf\&Itemid=30192>. Acesso em: $02 \mathrm{dez}$. 2019 .

BRASIL. Lei $\mathrm{n}^{\circ}$ 13.005. Instituto Nacional de Estudos e Pesquisas Educacionais Anísio Teixeira. Plano Nacional de Educação PNE 2014-2024: Linha de Base. Brasília, DF: Inep, 2015.

BRASIL. Ministério da Educação. Conselho Nacional de Educação. Base Nacional Comum Curricular. Brasília, 2018a. Disponível em: $<\mathrm{http}$ ///basenacionalcomum.mec.gov.br/images/BNCC_EI_EF_110518_versaofinal_ site.pdf>. Acesso em: 02 dez. 2019.

BRASIL. Ministérioda Educação. Novo Ensino Médio - perguntas e respostas. Brasilia, 2018 b. Disponível em: $<$ http://portal.mec.gov.br/component/article?id=40361>.

DALL'IGNA, M. A.; CÓSSIO, M. F. As Políticas Estaduais de Formação Continuada de Professores no Rio Grande do Sul (1990-2010). In: Anais... $25^{\circ}$ Simpósio Brasileiro e $2^{\circ}$ Congresso Ibero-Americano de Política. São Paulo, 2011. Disponível em: <http://www.anpae.org.br/simposio2011/cdrom2011/PDFs/trabalhosCompletos/com unicacoesRelatos/0334.pdf>. Acesso em: 12 dez. 2013.

FIORENTINI, D. Alguns modos de ver e conceber o ensino da matemática no Brasil. Zetetiké. Campinas, v.3, n. 4, 1995. p. 1-37.

FISCHER, M.C. B. A experiência das classes - piloto organizadas pelo GEEMPA, ao tempo da matemática moderna. Diálogo Educacional, Curitiba, v. 6, 2006, n. 8, p. $101-112$.

FISCHER, M. C. B. et al. História do Movimento da Matemática Moderna no Brasil: Arquivos e Fontes. Guarapuava: SBHMat, 2007.

GROSSI, E. P. Uma arqueologia dos saberes do Geempa. Revista GEEMPA (35 anos). Porto Alegre, n. 10, p. 11-39, set. 2005.

GROSSI, E. P. O GEEMPA, uma vivíssima ONG. Em Aberto. Brasília, v. 14, n.62, p. 97-99, abr./jun. 1994.

MELLO, E. M. B. A Política de Valorização e de Profissionalização dos Professores da Educação Básica do Estado do Rio Grande do Sul (1995-2006): convergências e divergências. 2010. Tese - Faculdade de Educação. UFRGS. Programa de PósGraduação em Educação, 2010, Porto Alegre.

NACARATO, A. M.; MENGALI; B. L.S.; PASSOS, C. L. B. A Matemática nos anos iniciais do ensino fundamental: tecendo fios do ensinar e do aprender. Belo Horizonte: Autêntica, 2009. 
NASCIMENTO, M. N. M. Ensino Médio no Brasil: determinações históricas. UEPG, Ponta Grossa, v. 15, n. 1, jun. 2007. p. 77-87. Disponível em: <http://www.revistas2.uepg.br/index.php/humanas/article/view/594> Acesso em: 05 jun. 2012.

PEREIRA, L. H. F. Os discursos sobre a matemática publicados na Revista do Ensino do Rio Grande do Sul - (1951 - 1978). 2010. Tese (Doutorado em Educação). Pontifícia Universidade Católica do Rio Grande do Sul, Porto Alegre, 2010.

PIRES, C. M. C. Currículo de Matemática: da organização linear a ideia de rede. São Paulo: FTD, 2000.

PIRES, C. M. C. Educação Matemática e sua Influência no Processo de Organização e Desenvolvimento Curricular no Brasil. In: Bolema, São Paulo, n 29, ano 21, 2008. p. 1- 42 .

RIO GRANDE DO SUL. Secretaria de Estado da Educação. Projeto Melhoria da qualidade de Ensino. Porto Alegre. 1993.

RIO GRANDE DO SUL. Secretaria de Estado da Educação. Padrão Referencial de Currículo - $1^{\mathrm{a}}$ versão. Porto Alegre, 1998.

RIO GRANDE DO SUL. Secretaria de Estado da Educação. Constituinte Escolar. Fundamentação, Objetivos e Momentos da Constituinte Escolar. Caderno 1, Texto Base, 1999.

RIO GRANDE DO SUL. Secretaria de Estado da Educação. Princípios e Diretrizes para a Educação Pública Estadual. Porto Alegre: Corag, 2000.

RIO GRANDE DO SUL. Secretaria de Estado da Educação. Relatório de Ações da Secretaria Estadual da Educação. Porto Alegre, 2006.

RIO GRANDE DO SUL. Secretaria de Estado da Educação. Departamento Pedagógico. Lições do Rio Grande: Referencial Curricular / Ensino Fundamental. Porto Alegre: SE/DP, 2009.

RIO GRANDE DO SUL. Secretaria de Estado da Educação. Lições do Rio Grande. 2010. Disponível em: <http://www.educacao.rs.gov.br/pse/html/refer_curric.jsp>. Acesso em: 12 out. 2013.

RIO GRANDE DO SUL. Secretaria de Estado da Educação. Lições do Rio Grande. 2010a. Disponível em: <http://www.educacao.rs.gov.br/dados/refer_curric_prof_vol1.pdf>. Acesso em: 12 out. 2013.

RIO GRANDE DO SUL. Secretaria de Estado da Educação. Departamento Pedagógico. Proposta Pedagógica para o Ensino Médio Politécnico e Educação Profissional Integrada ao Ensino Médio. Porto Alegre: SE/DP, 2011.

RIO GRANDE DO SUL. Secretaria de Estado da Educação. Departamento 
Pedagógico. Regimento Referência das escola de Ensino Médio Politécnico da Rede Estadual de Ensino. Porto Alegre: SE/DP, 2012.Disponível: http://www.mat.ufrgs.br/ppgem/forum/regimento_referencia_politecnico.pdf Acesso em: 12 jan. 2014.

RIO GRANDE DO SUL. Secretaria da Educação. Sistema de Avaliação do Rendimento Escolar do RS - SAERS. Disponível em: $<$ http://www.educacao.rs.gov.br/pse/html/saers.jsp?ACAO=acao1>. Acesso em: 12 jan. 2014.

RIO GRANDE DO SUL. Secretaria de Estado da Educação. Departamento Pedagógico. União Nacional dos Dirigentes Municipais de Educação. Referencial Curricular Gaúcho: matemática. Porto Alegre: SE/DP, 2018.

Recebido em dezembro de 2019.

Aprovado em fevereiro de 2020. 